\title{
Complications of external cerebrospinal fluid drainage in aneurysmal subarachnoid haemorrhage
}

\author{
Sebastian Arts ${ }^{1}$ (D) Erik J. van Lindert ${ }^{1} \cdot$ Rene Aquarius $^{1} \cdot$ Ronald H. M. A. Bartels $^{1} \cdot$ Hieronymus D. Boogaarts $^{1}$
}

Received: 30 September 2020 / Accepted: 14 December 2020 / Published online: 2 January 2021

(C) The Author(s) 2021

\begin{abstract}
Background The need for external cerebrospinal fluid (CSF) drains in aneurysmal subarachnoid haemorrhage (aSAH) patients is common and might lead to additional complications.

Objective A relation between the presence of an external CSF drain and complication risk is investigated.

Methods A prospective complication registry was analysed retrospectively. We included all adult aSAH patients admitted to our academic hospital between January 2016 and January 2018, treated with an external CSF drain. Demographic data, type of external drain used, the severity of the aSAH and complications, up to 30 days after drain placement, were registered. Complications were divided into (1) complications with a direct relation to the external CSF drain and (2) complications that could not be directly related to the use of an external CSF drain referred to as medical complications

Results One hundred and forty drains were implanted in $100 \mathrm{aSAH}$ patients. In total, 112 complications occurred in 59 patients. Thirty-six complications were drain related and 76 were medical complications. The most common complication was infection $(n$ $=34)$. Drain dislodgement occurred 16 times, followed by meningitis $(n=11)$ and occlusion $(n=9)$. A Poisson model showed that the mean number of complications raised by $2.9 \%$ for each additional day of drainage (95\% CI: $0.6-5.3 \% p=0.01$ ).

Conclusion Complications are common in patients with aneurysmal subarachnoid haemorrhage of which $32 \%$ are drain-related. A correlation is present between drainage period and the number of complications. Therefore, reducing drainage period could be a target for further improvement of care.
\end{abstract}

Keywords Complications $\cdot$ Hydrocephalus $\cdot$ External cerebrospinal fluid drain $\cdot$ Subarachnoid haemorrhage

\section{Introduction}

External cerebrospinal fluid (CSF) drainage is a frequently performed neurosurgical procedure [13, 26]. Most of the external drain placements occur in an emergency setting and patients are often admitted to the intensive care unit (ICU) afterwards.

External lumbar and ventricular drainage are two treatment methods for hydrocephalus in aneurysmal subarachnoid

This article is part of the Topical Collection on CSF Circulation

Sebastian Arts

Sebastian.arts@radboudumc.nl

Hieronymus D. Boogaarts

Jeroen.boogaarts@radboudumc.nl

1 Department of Neurosurgery, Radboud University Medical Center, Geert Grooteplein-Zuid 10, P.O. Box 9101, 6500

HB Nijmegen, The Netherlands haemorrhage (aSAH) patients [12, 21, 30]. Hydrocephalus occurs in about $20 \%$ of cases [37, 51]. Of all aSAH patients with hydrocephalus, $26 \%$ to $83 \%$ requires external ventricular drainage [37, 51]. Hydrocephalus can be either communicating or non-communicating. In the case of communicating hydrocephalus, placement of an external lumbar drain (ELD) can be taken into consideration. Although not as widely used as external ventricular drainage, external lumbar drainage shows some advantages regarding the incidence of vasospasm [12, 30]. Though if the ventricular outflow is obstructed by subarachnoid haemorrhage remnants, it is necessary to place an external ventricular drain (EVD).

It is known that CSF infection, drain malposition and drain dislodgement are common drainage-related complications [1, $19,22,50]$. In addition, aSAH patients have other complications, not directly related to CSF drainage, such as pneumonia or thromboembolic processes $[5,55,56]$. The influence of external cerebrospinal fluid drains on developing these general complications has not been described previously to our 
knowledge. We hypothesize that complications are common in aSAH patients treated with an external drain and that drainrelated complications form a substantial part of the total amount of complication.

This study evaluates the general (referred to as medical) complications and CSF drainage-related complications. A relation between the presence of an external CSF drain and the medical complication risk is investigated.

\section{Methods and materials}

A prospective complication registry held at the Radboud University Medical Center was retrospectively evaluated. All adult patients ( $>18$ years) diagnosed with aSAH in the period January 2016 until January 2018 treated with an EVD (Codman ${ }^{\circledR}$ Bactiseal ${ }^{\circledR}$ EVD Catheter or ELD (Duet ${ }^{\mathrm{TM}}$ External Drainage and Monitoring System) were included. Patients were identified according to the procedure codes within the hospital registry system.

Patients were excluded if they received an EVD or ELD before transferral to our hospital, if they were admitted due to complications of previous surgery or if they died within $24 \mathrm{~h}$ after admission.

The drainage system used was based on the principle of communicating vessels, using an overflow reservoir calibrated at the foramen of Monro. Our local protocol prescribes drain closure during mobilization which is allowed for a maximum of $30 \mathrm{~min}$, three times a day.

Patient-specific data were retrieved from the digital patient information system (Epic Systems Corporation (2014), Madison, Wisconsin, USA). Information regarding demographics, drainage period, drain type, length of hospital stay, destination after discharge and complications were obtained. Complications were defined as any unfavourable event which required additional medical treatment. Complications were included if these occurred between drain placement until 30 days after drain removal. If patients received more than one drain, the drainage period and therefore the timing of complications was calculated from the day the first drain was inserted.

Complications were divided into complications with a direct relation to the external CSF drain, which means drain dislodgement, drain occlusion and meningitis and complications that could not be directly related to the external cerebrospinal fluid drain referred to as medical complications. Medical complications were divided into four subgroups (Table 3). Furthermore, the number of internal shunts after external drain placement was retrieved.

Thrombo-embolic processes were subdivided into deep vein thrombosis (DVT) and pulmonary embolisms (PE). DVT consisted of a confirmed diagnosis by echo-Doppler, while for PE, a confirmed diagnosis by spiral-CT scan was required. Delirium was registered as a complication when patients had clinical signs of delirium according to the Delirium Observation Scale (DOS) for which haloperidol was given [45]. Pressure injuries were defined by the pressure injury grading score as stated by the National pressure Ulcer Advisory Panel (NPUAP) in 2016 [15]. An infection was only registered as a complication if treatment was started. An infection was detected by monitoring the clinical condition of the patient combined with a rising CRP and leukocyte count or positive cultures. An EVD or ELD was considered to be dislodged when the drain inadvertently was partially or entirely removed. Occlusion was registered as complication if drain reimplantation was needed.

Delayed cerebral ischemia (DCI), according to the definition of Vergouwen et al., was analyzed as a possible contributing factor to the incidence of complications as it is related to the severity of disease [54].

Data were analysed in IBM SPSS Statistics for Windows (Version 22.0. IBM Corp. Armonk, NY, USA). Continuous data are presented as mean and standard deviation when normally distributed or median and range when not normally distributed. Categorical data were presented as counts and percentages. The incidence of complications over time was visualized in a Kaplan-Meier curve. Differences in mean or median were tested using an independent Student's $t$ test or Mann-Whitney $U$ test, respectively. Additionally, a KruskalWallis test was performed to check for statistical difference in drainage period between patients with different WFNS scores.

Based on the expected distribution, a Poison regression model was used in which the number of drains was grouped due to the low number of patients receiving more than three drains.

In all the analyses, a patient with drain-related complication is presented as a patient with one or more drain-related complications regardless of any medical complications.

Significance was defined as $p<0.05$.

\section{Results}

\section{Demographics}

Between January 2016 and January 2018, 140 drain placements (79 EVD; 61 ELD) were performed in 100 aSAH patients. The mean number of drains per patient was 1.4 (SD = 0.80 ). Demographics are given in Table 1. A total of 112 complications occurred in 59 patients with a mean of $1.9 \mathrm{com}-$ plications per patient (Fig. 1). Thirty-three (33\%) patients were discharged to their home situation, $30(30 \%)$ to other departments or hospitals and 24 (24\%) patients died.

\section{Drain-related complications}

Thirty-six drain-related complications occurred in 26 patients (Table 2). The mean number of drains in patients with 
Table 1 Demographic data. Numbers are presented as counts, mean and standard deviation or median and range. Statistically significant difference between patients with and without complications was calculated by independent Student's $t$ test or Mann-Whitney $U$ test

\begin{tabular}{|c|c|c|c|c|c|}
\hline & & Total & With complication & Without complication & Significance level \\
\hline Number of patients & & 100 & 59 & 41 & N/A \\
\hline \multirow[t]{2}{*}{ Gender } & Male & 20 & 11 & 9 & N/A \\
\hline & Female & 80 & 48 & 32 & N/A \\
\hline \multirow{3}{*}{$\begin{array}{l}\text { Number of patients with } \\
\text { each drain type }\end{array}$} & ELD & 32 & 16 & 16 & \multirow[t]{3}{*}{ N/A } \\
\hline & EVD & 47 & 22 & 25 & \\
\hline & Both & 21 & 21 & 0 & \\
\hline Age (years) & & $58(12)$ & $59(11)$ & $56(13)$ & $P=0.210$ \\
\hline WFNS & & $3.0(1.5)$ & $3.1(1.5)$ & $3.0(1.6)$ & $P=0.746$ \\
\hline DCI & & $0.27(0.45)$ & $0.32(0.47)$ & $0.20(0.40)$ & $P=0.151$ \\
\hline ASA & & $1.8(0.79)$ & $1.8(0.78)$ & $1.8(0.81)$ & $P=0.959$ \\
\hline LOS (days) & & $17(2-91)$ & $21(4-91)$ & $11(2-26)$ & $P=0.00$ \\
\hline Number of drains & & $1.4(0.80)$ & $1.7(1.0)$ & $1.0(0.00)$ & $P=0.00$ \\
\hline Drainage time (days) & & $10(1-48)$ & $13(1-48)$ & $7.0(1-17)$ & $P=0.00$ \\
\hline Number of VPD insertions & & 15 & 14 & 1 & N/A \\
\hline
\end{tabular}

meningitis was $2.8(\mathrm{SD}=1.3)$ versus $1.2(\mathrm{SD}=0.5)$ in patients without meningitis $(p=0.03)$. Although the median time from first drain placement to meningitis was 21 days (range 5-33), the median time from last drain placement until meningitis was 4 days (range 0-24). Drain dislodgements occurred 16 times in 14 patients. In nine cases, a new drain was placed: four times an EVD, five times an ELD. Drain occlusion occurred 9 times in 8 patients, with a median time between last drain placement and occlusions of 5 days (range 1-20).

\section{Medical complications}

Medical complications ranged from 1 to 4 complications per patient (Fig. 1, Table 3). Although there was no overall significant difference in mean WFNS score in patients with and without medical complications (independent Student's $t$ test, $p$ $=0.74)$, patients with pressure sores had a significant higher WFNS score (independent Student's $t$ test $p=0.001$ )

Median duration between admission and first drain placement was 0 days (range $0-10$ ) The median duration between

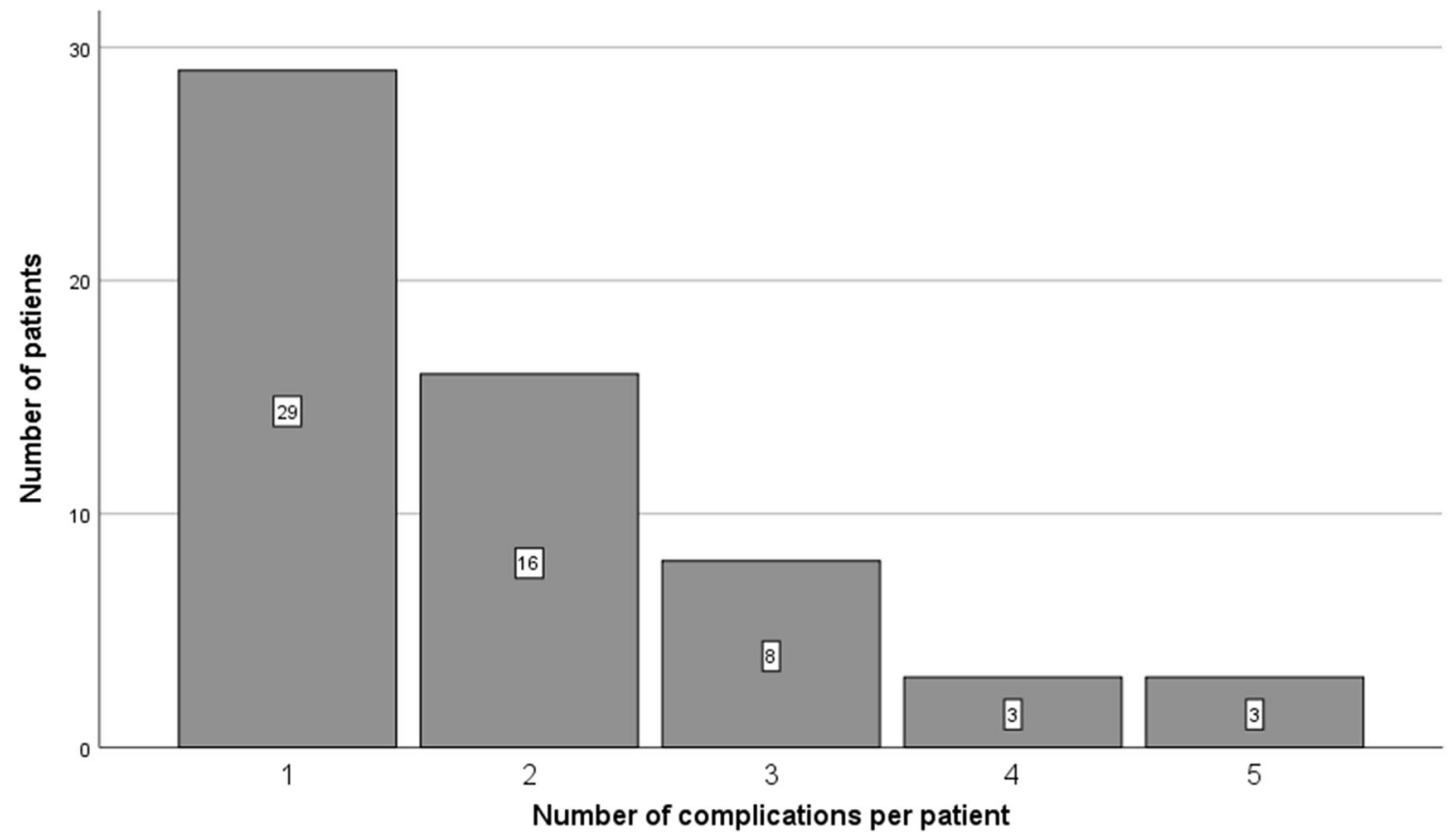

Fig. 1 The number of complications per patient 
Table 2 Drain-related complications in counts and percentages. Drainage period was presented as median and range

\begin{tabular}{llll}
\hline & Number of patients & EVD/ELD & Drainage period in days \\
\hline Meningitis & $11(31 \%)$ & $11: 0$ & $30(13-48)$ \\
Dislodgement & $16(44 \%)$ & $14: 2$ & $13(4-35)$ \\
Occlusion & $9(25 \%)$ & $7: 2$ & $19(7-42)$ \\
Total & $36(100 \%)$ & $32: 4$ & $20(4-48)$ \\
\hline
\end{tabular}

drain placement and the first medical complication was 6.5 days (range 0-59). For the second and third complication, this was 11 (range 2-73) and 17 (range 6-21) days, respectively. One patient had a fourth medical complication occurring at 38 days after drain placement.

Figure 2 shows the incidence of complications over time presented as an inverse survival curve, with a median overall survival rate of 8 days.

DCI occurred in 27 patients. The mean time between admission or drain placement and DCI was $6.7(\mathrm{SD}=4.8)$ and $5.7(\mathrm{SD}=5.4)$ days, respectively. There was no statistically significant difference in the incidence of DCI between patients with and without complications $(p=0,151)$.

Table 4 shows the differences in patients with any complication, only medical complications or drain-related complications.

\section{Regression analysis}

Age, gender, ASA score, WFNS score, type of drains, number of drains (grouped: 1 drain, 2 drains or 3-5 drains) and drainage period were used as predictors in a Poisson regression analysis. This model showed that per day extra drainage period, the mean number of total complications raised by $2.9 \%$ (95\% CI: $0.6-5.3 \% p=0.01$ ). When only medical complications were taken into account, the mean number of complications per extra day drainage period raised by $4.0 \%$ (95\% CI: $1.0-7.0 \%, p=0.01)$. Besides, the regression analysis showed that receiving more than one drain significantly contributed to the number of complications when both medical and drainrelated complications were taken into account $(p \leq 0.01)$. However, no significant contribution was found regarding the number of drains when drain dislodgement and occlusion were excluded $(p=0.36)$.

No other confounders were found. A regression analysis regarding only drain-related complications could not be properly performed due to the low number of patients in subgroups.

As an addition, a Kruskal-Wallis test showed that drainage period was not the same across the different WFNS groups (WFNS 1, WFNS 2-3 and WFNS 4-5), with longer drainage periods in patients with higher WFNS scores $(p=0.00)$.

\section{Discussion}

This study revealed that complications are common in aSAH patients with hydrocephalus treated with an external cerebrospinal fluid drain and that the mean number of complications will raise per extra day drainage period.

Additionally, receiving more than one drain was a significant contributor to the number of complications when both medical and drain-related complications were taken into account. However, this is probably caused by the fact that, per definition, both luxation and occlusion require drain revision.

\section{Drain-related complications}

In order to minimize these drain-related complications, a decrease in drainage period and avoiding unnecessary manipulation and CSF samplings are essential [23, 25, 26].

Drainage for more than 8 days would increase the number in EVD-related infection compared with a drainage period of 7 days or less [26]. Another study suggests that a drainage
Table 3 Medical complications presented as number of patients and percentages. Drainage period is presented as median and range. Miscellaneous infections consisted of S. aureus bacteraemia, oral candidiasis and one patient that had clinical signs of infection without a proven focus treated with piperacillin/ tazobactam

\begin{tabular}{llll}
\hline & & Number of patients & Drainage period in days \\
\hline Infection & Urinary tract & $18(16 \%)$ & $13(1-37)$ \\
& Pneumonia & $13(12 \%)$ & \\
Miscellaneous & $3(8.8 \%)$ & $17(1-47)$ \\
Delirium & & $31(2.7 \%)$ & $26(13-42)$ \\
Pressure injuries & $8(7.1 \%)$ & $19(10-21)$ \\
Trombo-embolic process (2 PE, 1 DVT) & $3(2.7 \%)$ & $11(1-23)$ \\
Total & $76(100 \%)$ &
\end{tabular}




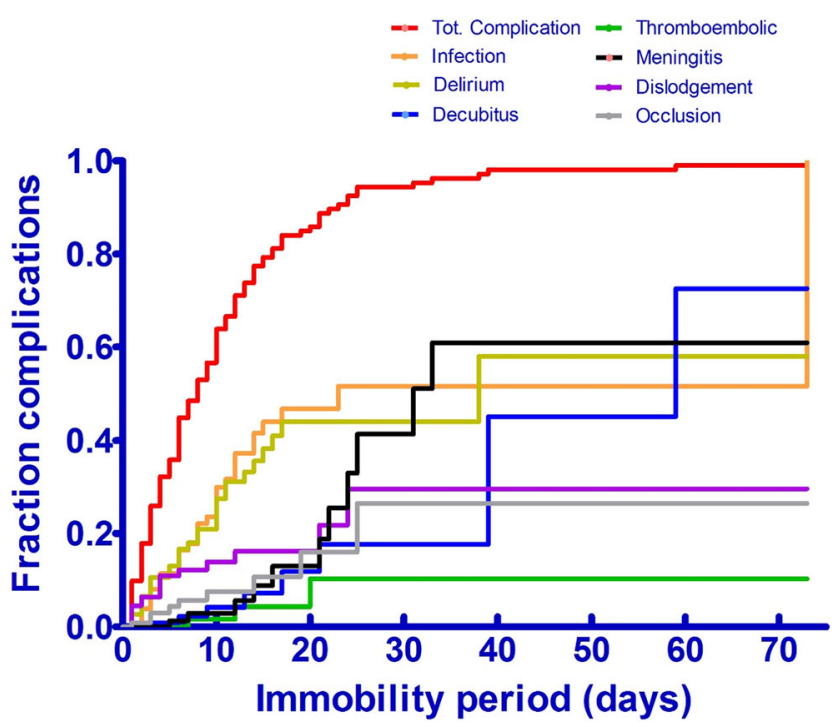

Fig. 2 The incidence of complications as a function of drainage period displayed as an inverse survival curve. Median survival 8 days

period longer than 11 days would significantly increase the risk of infection (OR 4.1; 95\% CI 1.8-9.2, $p=0.001$ ) and CSF sampling was significantly higher in patients with CSF infection $(4.0 \pm 3.7$ vs $1.4 \pm 1.8, p<0.001)[23]$.

The daily attributed risk for CSF infection might be underestimated or even a false correlation as colonization could already be induced during EVD insertion [33]. Moreover, frequent manipulation and opening of drains are significant contributors to the incidence of meningitis [25]. This could also be the case in this study, since the mean number of drains in patients with meningitis more than doubles the mean amount of drains in patients without meningitis.

The incidence of external ventricular drain dislodgements is sparsely described in literature. Few articles are published regarding different securing techniques, like tunnelling or roman sandal attachment $[1,53,58]$. Two of these articles publish a remarkably low rate of drain dislodgements 0 $0.4 \%[53,58]$. It is most likely that drain dislodgement is underreported and that the few numbers reported in literature are an underestimation. In our centre, no standardized method was used for EVD fixation. It is likely that a standardized protocol using proven securing techniques could contribute to lower drain dislodgement [52].

The usage of ELDs in patients with aSAH appears to be safe and seems to clear blood remnants more rapidly compared with EVDs [3, 16, 34]. Subsequently, the incidence of DCI decreased $[3,16]$. However, concerns regarding herniation continue to exist and outcome at 6 months after aSAH did not improve [3, 16, 34]. Since dislodgement is remarkably lower in patients treated with ELD and literature shows promising results regarding vasospasm, it seems beneficial to use ELD more frequently in patients with aSAH.

Incidence rates of EVD occlusion vary between 19 and $47 \%$ [9, 17, 41]. One dedicated study on EVD occlusion found that small catheter inner diameter $(1.5 \mathrm{~mm}$ versus 1.9 $\mathrm{mm}$ ) was significant risk factors for permanent EVD occlusion, with a three times higher odds [17]. In our study, only $1.5-\mathrm{mm}$ diameter catheters were used. Using a wider catheter seems to have no effect on the number of EVD-related haemorrhage [35]. Moreover, the clinical relevance of EVD-related haemorrhage is questionable [48]. Therefore, using a $1.9-\mathrm{mm}$ EVD catheter could reduce our permanent occlusion rate and seems to have no disadvantages regarding EVD-related haemorrhage.

\section{Medical complications}

Infections form a substantial part of complications after aSAH, in particular pneumonia and urinary tract infection
Table 4 Differences in patients with any complication, only medical complications or drainrelated complications. Drainrelated complication is presented as a patient with one or more drain-related complications regardless of any medical complications. Numbers are presented as mean and standard deviation or median and range. Statistically significant difference between patients with medical and with drain-related complications was calculated by independent Student's $t$ test or Mann-Whitney $U$ test

\begin{tabular}{|c|c|c|c|c|c|}
\hline & & $\begin{array}{l}\text { Any } \\
\text { complication }\end{array}$ & $\begin{array}{l}\text { Medical } \\
\text { complication }\end{array}$ & $\begin{array}{l}\text { Drain-related } \\
\text { complication }\end{array}$ & $\begin{array}{l}\text { Significance } \\
\text { level }\end{array}$ \\
\hline Number of patients & & 59 & 33 & 26 & N/A \\
\hline \multirow[t]{2}{*}{ Gender } & Male & 11 & 5 & 6 & N/A \\
\hline & Female & 48 & 28 & 20 & N/A \\
\hline \multirow{3}{*}{$\begin{array}{l}\text { Number of patients with } \\
\text { each drain type }\end{array}$} & ELD & 16 & 16 & 0 & \multirow[t]{3}{*}{ N/A } \\
\hline & EVD & 22 & 14 & 8 & \\
\hline & Both & 21 & 3 & 18 & \\
\hline Age (years) & & $59(11)$ & $61(11)$ & $56(11)$ & $P=0.094$ \\
\hline WFNS & & $3.1(1.5)$ & $2.6(1.4)$ & $3.7(1.3)$ & $P=0.004$ \\
\hline DCI & & $0.32(0.47)$ & $0.33(0.48)$ & $0.31(0.47)$ & $P=0.838$ \\
\hline ASA & & $1.8(0.78)$ & $2.0(0.81)$ & $1.6(0.70)$ & $P=0.055$ \\
\hline LOS (days) & & $21(4-91)$ & $18(4-42)$ & $29(7-91)$ & $P=0.013$ \\
\hline Number of drains & & $1.7(1.0)$ & $1.1(0.29)$ & $2.4(1.0)$ & $P=0.002$ \\
\hline Drainage time (days) & & $13(1-48)$ & $11(1-23)$ & $20(4-48)$ & $P=0.008$ \\
\hline Number of VPD insertions & & 14 & 3 & 11 & N/A \\
\hline
\end{tabular}


$[10,20]$. These complications are related to a longer length of stay $[10,20]$. Infections are a common problem in critically hospitalized patients in particular in patients with severe neurological disease $[4,24,36]$. However, our study showed no difference in mean WFNS score between patients with and without infection. Possibly, because WFNS score was reported at admission and does not take into account later neurological improvement or decline.

For pressure sores, incidence rates vary from 1.58 to $62.5 \%$, with higher rates in departments where patients are less ambulant, i.e. intensive care units and neurological departments $[2,7,18,27]$. Pressure sores are of multifactorial origin [6]. The same applies to delirium. Many factors could contribute to the occurrence of postoperative delirium [ $[42$, 47], including ambulatory status $[8,28]$. As a result, it is challenging to determine the effect of factors that contribute to the development of pressure sores and delirium.

Thrombo-embolic processes are relatively uncommon in aSAH patients, with an incidence of deep venous thrombosis in aSAH patients ranging from 4.4 to $6.7 \%[29,31]$ and for pulmonary embolism $2 \%[44,46]$. Literature suggests sonographic screening for deep venous thrombosis in aSAH patients in order to detect subclinical deep venous thrombi, with a detected DVT rate of 9.7-25\% [44, 46]. However, it is questionable what the clinical relevance of these detected subclinical thrombosis might be.

\section{Medical complications and their relation to external CSF drainage}

The relatively high number of complications in this series, compared with literature $[39,47,60]$, could be caused by the neurological impairment, i.e. severity of disease in our patient population. Nevertheless, it is remarkable that drainage period had a significant impact on the amount of complications, even when only medical complications were taken into account and without a significant contribution of WFNS score, i.e. medical condition. Immobility can lead to complications and subsequent morbidity, mortality and a considerable financial burden $[11,49,57,59]$. Although no proper control group was used, i.e. patients with aSAH without drain, patients with an EVD or ELD could be more prone to complications due to the relative immobility after drain placement $[14,49]$. Nota bene, although WFNS scores did not show a significant effect on the amount of complications, it should be taken into account that patients with higher WFNS scores seem to have a longer drainage period, which means that clinical condition could play a part in the higher amount of complications in patients with longer drainage period. This again emphasizes the multifactorial origin of complications which can cause bias when searching for causality.

However, to minimize the contribution of immobilization on complication rate, early mobilization protocols could be beneficial and appear to be safe $[38,61,62]$. Probably, the beneficial effect only applies to complications with a strong correlation to immobilization. For example, thrombo-embolic processes or pressure sores are more likely to be strongly correlated with immobilization than infection. Therefore, decline in complications in mobile patients is expected from a subgroup of complications instead of the entire spectrum. Moreover, complications of immobility are significantly associated with reduced health-related quality of life [60].

The current drainage system in many centres is based on the principle of communicating vessels, using an overflow reservoir. This reservoir is calibrated at the height of the foramen of Monro which hinders a patient's movements as the reservoir needs to remain at the level of the foramen of Monro at all time to prevent severe fluctuations in CSF draining. Digital systems enabling mobilization and early EVD weaning with an external cerebrospinal fluid drain might contribute to early mobilization and therefore might help reducing the number of complications [32, 43].

\section{Limitations}

This study suffers from its retrospective nature; however, prospective data acquisition was performed, which declines the chance of underreporting. Moreover, in order to further minimize underreporting, individual patient charts were evaluated. A second limitation is that due to the study design and multifactorial origin of complications, it is hard to determine which complications are causally related to external ventricular drainage and which are related to hospitalization and immobilization on a more general level.

Mortality in this study was in concordance to what is reported in literature [40]. However, results could be influenced by patients that died shortly after their admission to the ICU, since the length of stay in these patients was mostly insufficient to develop any complications related to immobility.

One major drawback is that no proper control group was used, i.e. patients with subarachnoid haemorrhage without drain placement. It could be that the medical complications are a result of the disease instead of the immobility caused by drain placement. Moreover, patients requiring an external drain are assumed to be in a worse condition compared with patients without.

\section{Conclusion}

Complications are common in patients with aneurysmal subarachnoid haemorrhage of which $32 \%$ are drain-related. A correlation is present between drainage period and the number of complications. Therefore, reducing drainage period could be a target for further improvement of care. 


\section{Compliance with ethical standards}

Conflict of interest All authors certify that they have no affiliations with or involvement in any organization or entity with any financial interest (such as honoraria; educational grants; participation in speakers' bureaus; membership, employment, consultancies, stock ownership, or other equity interest; and expert testimony or patent-licensing arrangements), or non-financial interest (such as personal or professional relationships, affiliations, knowledge or beliefs) in the subject matter or materials discussed in this manuscript.

Ethical approval All procedures performed in studies involving human participants were in accordance with the ethical standards of the institutional board review (NL62883.091.17) and with the 1964 Helsinki declaration and its later amendments or comparable ethical standards.

Informed consent For this type of study, formal consent is not required.

Open Access This article is licensed under a Creative Commons Attribution 4.0 International License, which permits use, sharing, adaptation, distribution and reproduction in any medium or format, as long as you give appropriate credit to the original author(s) and the source, provide a link to the Creative Commons licence, and indicate if changes were made. The images or other third party material in this article are included in the article's Creative Commons licence, unless indicated otherwise in a credit line to the material. If material is not included in the article's Creative Commons licence and your intended use is not permitted by statutory regulation or exceeds the permitted use, you will need to obtain permission directly from the copyright holder. To view a copy of this licence, visit http://creativecommons.org/licenses/by/4.0/.

\section{References}

1. Akarca D, Durnford AJ, Ewbank FG, Hempenstall J, Sadek AR, Gould AER, Bulters DO (2018) An evaluation of commonly used external ventricular drain securement methods in a porcine model: recommendations to improve practice. World Neurosurg 110: e197-e202. https://doi.org/10.1016/j.wneu.2017.10.138

2. Allman RM, Laprade CA, Noel LB, Walker JM, Moorer CA, Dear MR, Smith CR (1986) Pressure sores among hospitalized patients. Ann Intern Med 105:337-342

3. Al-Tamimi YZ, Bhargava D, Feltbower RG, Hall G, Goddard AJ, Quinn AC, Ross SA (2012) Lumbar drainage of cerebrospinal fluid after aneurysmal subarachnoid hemorrhage: a prospective, randomized, controlled trial (LUMAS). Stroke 43:677-682. https://doi.org/ 10.1161/STROKEAHA.111.625731

4. Berrouane Y, Daudenthun I, Riegel B, Emery MN, Martin G, Krivosic R, Grandbastien B (1998) Early onset pneumonia in neurosurgical intensive care unit patients. J Hosp Infect 40:275-280. https://doi.org/10.1016/s0195-6701(98)90303-6

5. Beseoglu K, Holtkamp K, Steiger HJ, Hanggi D (2013) Fatal aneurysmal subarachnoid haemorrhage: causes of 30-day in-hospital case fatalities in a large single-centre historical patient cohort. Clin Neurol Neurosurg 115:77-81. https://doi.org/10.1016/j.clineuro. 2012.10.011

6. Bhattacharya S, Mishra RK (2015) Pressure ulcers: current understanding and newer modalities of treatment. Indian J Plast Surg 48: 4-16. https://doi.org/10.4103/0970-0358.155260

7. Borghardt AT, Prado TN, Bicudo SD, Castro DS, Bringuente ME (2016) Pressure ulcers in critically ill patients: incidence and associated factors. Rev Bras Enferm 69:460-467. https://doi.org/10. 1590/0034-7167.2016690307i
8. Brummel NE, Girard TD (2013) Preventing delirium in the intensive care unit. Crit Care Clin 29:51-65. https://doi.org/10.1016/j. ccc.2012.10.007

9. Chi H, Chang KY, Chang HC, Chiu NC, Huang FY (2010) Infections associated with indwelling ventriculostomy catheters in a teaching hospital. Int J Infect Dis 14:e216-e219. https://doi.org/ 10.1016/j.jijid.2009.04.006

10. Dasenbrock HH, Rudy RF, Smith TR, Guttieres D, Frerichs KU, Gormley WB, Aziz-Sultan MA, Du R (2016) Hospital-acquired infections after aneurysmal subarachnoid hemorrhage: a nationwide analysis. World Neurosurg 88:459-474. https://doi.org/10.1016/j. wneu.2015.10.054

11. Dealey C, Posnett J, Walker A (2012) The cost of pressure ulcers in the United Kingdom. J Wound Care 21:261-262, 264, 266. https:// doi.org/10.12968/jowc.2012.21.6.261

12. Demetriades AK, Tolias C (2011) Lumbar drainage in aneurysmal subarachnoid haemorrhage. Br J Neurosurg 25:537. https://doi.org/ 10.3109/02688697.2011.558947

13. Dey M, Jaffe J, Stadnik A, Awad IA (2012) External ventricular drainage for intraventricular hemorrhage. Curr Neurol Neurosci Rep 12:24-33. https://doi.org/10.1007/s11910-011-0231-x

14. Dittmer DK, Teasell R (1993) Complications of immobilization and bed rest. Part 1: Musculoskeletal and cardiovascular complications. Can Fam Physician 39:1428-1432 1435-1427

15. Edsberg LE, Black JM, Goldberg M, McNichol L, Moore L, Sieggreen M (2016) Revised national pressure ulcer advisory panel pressure injury staging system: revised pressure injury staging system. J Wound Ostomy Continence Nurs 43:585-597. https://doi. org/10.1097/WON.0000000000000281

16. Fang Y, Shao Y, Lu J, Dong X, Zhao X, Zhang J, Chen S (2020) The effectiveness of lumbar cerebrospinal fluid drainage in aneurysmal subarachnoid hemorrhage with different bleeding amounts. Neurosurg Rev 43:739-747. https://doi.org/10.1007/s10143-01901116-1

17. Fargen KM, Hoh BL, Neal D, O'Connor T, Rivera-Zengotita M, Murad GJ (2016) The burden and risk factors of ventriculostomy occlusion in a high-volume cerebrovascular practice: results of an ongoing prospective database. J Neurosurg 124:1805-1812. https:// doi.org/10.3171/2015.5.JNS15299

18. Fernandes LM, Caliri MH (2008) Using the Braden and Glasgow scales to predict pressure ulcer risk in patients hospitalized at intensive care units. Rev Lat Am Enfermagem 16:973-978

19. Fried HI, Nathan BR, Rowe AS, Zabramski JM, Andaluz N, Bhimraj A, Guanci MM, Seder DB, Singh JM (2016) The insertion and management of external ventricular drains: an evidence-based consensus statement : a statement for healthcare professionals from the Neurocritical Care Society. Neurocrit Care 24:61-81. https:// doi.org/10.1007/s12028-015-0224-8

20. Frontera JA, Fernandez A, Schmidt JM, Claassen J, Wartenberg KE, Badjatia N, Parra A, Connolly ES, Mayer SA (2008) Impact of nosocomial infectious complications after subarachnoid hemorrhage. Neurosurgery 62:80-87; discussion 87 . https://doi.org/10. 1227/01.NEU.0000311064.18368.EA

21. Gigante P, Hwang BY, Appelboom G, Kellner CP, Kellner MA, Connolly ES (2010) External ventricular drainage following aneurysmal subarachnoid haemorrhage. Br J Neurosurg 24:625-632. https://doi.org/10.3109/02688697.2010.505989

22. Governale LS, Fein N, Logsdon J, Black PM (2008) Techniques and complications of external lumbar drainage for normal pressure hydrocephalus. Neurosurgery 63:379-384; discussion 384. https:// doi.org/10.1227/01.NEU.0000327023.18220.88

23. Hoefnagel D, Dammers R, Ter Laak-Poort MP, Avezaat CJ (2008) Risk factors for infections related to external ventricular drainage. Acta Neurochir 150:209-214; discussion 214. https://doi.org/10. 1007/s00701-007-1458-9 
24. Hsieh AH, Bishop MJ, Kubilis PS, Newell DW, Pierson DJ (1992) Pneumonia following closed head injury. Am Rev Respir Dis 146: 290-294. https://doi.org/10.1164/ajrccm/146.2.290

25. Hussein K, Rabino G, Feder O, Eghbaryeh H, Zayyad H, Sviri G, Benenson R, Paul M (2019) Risk factors for meningitis in neurosurgical patients with cerebrospinal fluid drains: prospective observational cohort study. Acta Neurochir 161:517-524. https://doi.org/ 10.1007/s00701-019-03801-y

26. Jamjoom AAB, Joannides AJ, Poon MT, Chari A, Zaben M, MAH A, Roach J, Glancz LJ, Solth A, Duddy J, Brennan PM, Bayston R, Bulters DO, Mallucci CL, Jenkinson MD, Gray WP, Kandasamy J, Hutchinson PJ, Kolias AG, Ahmed AI, British Neurosurgical Trainee Research C (2018) Prospective, multicentre study of external ventricular drainage-related infections in the UK and Ireland. $\mathrm{J}$ Neurol Neurosurg Psychiatry 89:120-126. https://doi.org/10.1136/ jnnp-2017-316415

27. Jiang Q, Li X, Qu X, Liu Y, Zhang L, Su C, Guo X, Chen Y, Zhu Y, Jia J, Bo S, Liu L, Zhang R, Xu L, Wu L, Wang H, Wang J (2014) The incidence, risk factors and characteristics of pressure ulcers in hospitalized patients in China. Int J Clin Exp Pathol 7:2587-2594

28. Kawaguchi Y, Kanamori M, Ishihara H, Abe Y, Nobukiyo M, Sigeta T, Hori T, Kimura T (2006) Postoperative delirium in spine surgery. Spine J 6:164-169. https://doi.org/10.1016/j.spinee.2005. 06.010

29. Kim KS, Brophy GM (2009) Symptomatic venous thromboembolism: incidence and risk factors in patients with spontaneous or traumatic intracranial hemorrhage. Neurocrit Care 11:28-33. https://doi.org/10.1007/s12028-009-9201-4

30. Klimo P Jr, Kestle JR, MacDonald JD, Schmidt RH (2004) Marked reduction of cerebral vasospasm with lumbar drainage of cerebrospinal fluid after subarachnoid hemorrhage. J Neurosurg 100:215224. https://doi.org/10.3171/jns.2004.100.2.0215

31. Kshettry VR, Rosenbaum BP, Seicean A, Kelly ML, Schiltz NK, Weil RJ (2014) Incidence and risk factors associated with inhospital venous thromboembolism after aneurysmal subarachnoid hemorrhage. J Clin Neurosci 21:282-286. https://doi.org/10.1016/j. jocn.2013.07.003

32. Kwon YS, Lee YH, Cho JM (2016) Early experience of automated intraventricular type intracranial pressure monitoring (LiquoGuard(R)) for severe traumatic brain injury patients. Korean J Neurotrauma 12:28-33. https://doi.org/10.13004/kjnt. 2016.12.1.28

33. Lo CH, Spelman D, Bailey M, Cooper DJ, Rosenfeld JV, Brecknell JE (2007) External ventricular drain infections are independent of drain duration: an argument against elective revision. J Neurosurg 106:378-383. https://doi.org/10.3171/jns.2007.106.3.378

34. Maeda Y, Shirao S, Yoneda H, Ishihara H, Shinoyama M, Oka F, Sadahiro H, Ueda K, Sano Y, Kudomi S, Hayashi Y, Shigeeda T, Nakano K, Koizumi H, Nomura S, Fujii M, Nomura S, Suzuki M (2013) Comparison of lumbar drainage and external ventricular drainage for clearance of subarachnoid clots after Guglielmi detachable coil embolization for aneurysmal subarachnoid hemorrhage. Clin Neurol Neurosurg 115:965-970. https://doi.org/10.1016/j. clineuro.2012.10.001

35. Maniker AH, Vaynman AY, Karimi RJ, Sabit AO, Holland B (2006) Hemorrhagic complications of external ventricular drainage. Neurosurgery 59:ONS419-424; discussion ONS424-415. https:// doi.org/10.1227/01.NEU.0000222817.99752.E6

36. Meert KL, Long M, Kaplan J, Sarnaik AP (1995) Alterations in immune function following head injury in children. Crit Care Med 23:822-828. https://doi.org/10.1097/00003246-199505000-00008

37. Milhorat TH (1987) Acute hydrocephalus after aneurysmal subarachnoid hemorrhage. Neurosurgery 20:15-20. https://doi.org/10. 1227/00006123-198701000-00004

38. Moyer M, Young B, Wilensky EM, Borst J, Pino W, Hart M, LoBreglio J, Zaleski D, Leonor I, Kung D, Smith M, Zager E,
Grady MS, Kumar M (2017) Implementation of an early mobility pathway in neurointensive care unit patients with external ventricular devices. J Neurosci Nurs 49:102-107. https://doi.org/10.1097/ JNN.0000000000000258

39. Nicol M, Sun Y, Craig N, Wardlaw D (2009) Incidence of thromboembolic complications in lumbar spinal surgery in 1,111 patients. Eur Spine J 18:1548-1552. https://doi.org/10.1007/s00586-0091035-4

40. Oie LR, Solheim O, Majewska P, Nordseth T, Muller TB, Carlsen SM, Jensberg H, Salvesen O, Gulati S (2020) Incidence and case fatality of aneurysmal subarachnoid hemorrhage admitted to hospital between 2008 and 2014 in Norway. Acta Neurochir 162:22512259. https://doi.org/10.1007/s00701-020-04463-x

41. Olson DM, Zomorodi M, Britz GW, Zomorodi AR, Amato A, Graffagnino C (2013) Continuous cerebral spinal fluid drainage associated with complications in patients admitted with subarachnoid hemorrhage. J Neurosurg 119:974-980. https://doi.org/10. 3171/2013.6.JNS122403

42. Pioli G, Bendini C, Giusti A, Pignedoli P, Cappa M, Iotti E, Ferri MA, Bergonzini E, Sabetta E (2018) Surgical delay is a risk factor of delirium in hip fracture patients with mild-moderate cognitive impairment. Aging Clin Exp Res. https://doi.org/10.1007/s40520018-0985-y

43. Rao SS, Chung DY, Wolcott Z, Sheriff F, Khawaja AM, Lee H, Guanci MM, Leslie-Mazwi TM, Kimberly WT, Patel AB, Rordorf GA (2019) Intermittent CSF drainage and rapid EVD weaning approach after subarachnoid hemorrhage: association with fewer VP shunts and shorter length of stay. J Neurosurg:1-6. doi:https://doi. org/10.3171/2019.1.JNS182702

44. Ray WZ, Strom RG, Blackburn SL, Ashley WW, Sicard GA, Rich KM (2009) Incidence of deep venous thrombosis after subarachnoid hemorrhage. J Neurosurg 110:1010-1014. https://doi.org/10. 3171/2008.9.JNS08107

45. Schuurmans MJ, Shortridge-Baggett LM, Duursma SA (2003) The Delirium Observation Screening Scale: a screening instrument for delirium. Res Theory Nurs Pract 17:31-50

46. Serrone JC, Wash EM, Hartings JA, Andaluz N, Zuccarello M (2013) Venous thromboembolism in subarachnoid hemorrhage. World Neurosurg 80:859-863. https://doi.org/10.1016/j.wneu. 2013.01.012

47. Shi C, Yang C, Gao R, Yuan W (2015) Risk factors for delirium after spinal surgery: a meta-analysis. World Neurosurg 84:14661472. https://doi.org/10.1016/j.wneu.2015.05.057

48. Sussman ES, Kellner CP, Nelson E, McDowell MM, Bruce SS, Bruce RA, Zhuang Z, Connolly ES Jr (2014) Hemorrhagic complications of ventriculostomy: incidence and predictors in patients with intracerebral hemorrhage. J Neurosurg 120:931-936. https:// doi.org/10.3171/2013.12.JNS131685

49. Teasell R, Dittmer DK (1993) Complications of immobilization and bed rest. Part 2: Other complications. Can Fam Physician 39:1440 1442 1445-1446

50. Toma AK, Camp S, Watkins LD, Grieve J, Kitchen ND (2009) External ventricular drain insertion accuracy: is there a need for change in practice? Neurosurgery 65:1197-1200; discussion 1200-1191. https://doi.org/10.1227/01.NEU.0000356973.39913. $0 \mathrm{~B}$

51. van Gijn J, Hijdra A, Wijdicks EF, Vermeulen M, van Crevel H (1985) Acute hydrocephalus after aneurysmal subarachnoid hemorrhage. J Neurosurg 63:355-362. https://doi.org/10.3171/jns. 1985.63.3.0355

52. van Lindert EJ, Bilsen MV, Flier MV, Kolwijck E, Delye H, Oever JT (2018) Topical vancomycin reduces the cerebrospinal fluid shunt infection rate: A retrospective cohort study. PLoS One 13: e0190249. https://doi.org/10.1371/journal.pone.0190249

53. Velasquez C, Rivero-Garvia M, Mayorga-Buiza MJ, CanizaresMendez ML, Jimenez-Mejias ME, Marquez-Rivas J (2017) 
Avoiding pullout complications in external ventricular drains: technical note. J Neurosurg 126:1003-1005. https://doi.org/10.3171/ 2016.2.JNS1678

54. Vergouwen MD, Vermeulen M, van Gijn J, Rinkel GJ, Wijdicks EF, Muizelaar JP, Mendelow AD, Juvela S, Yonas H, Terbrugge KG, Macdonald RL, Diringer MN, Broderick JP, Dreier JP, Roos YB (2010) Definition of delayed cerebral ischemia after aneurysmal subarachnoid hemorrhage as an outcome event in clinical trials and observational studies: proposal of a multidisciplinary research group. Stroke 41:2391-2395. https://doi.org/10.1161/ STROKEAHA.110.589275

55. Wartenberg KE, Mayer SA (2006) Medical complications after subarachnoid hemorrhage: new strategies for prevention and management. Curr Opin Crit Care 12:78-84. https://doi.org/10.1097/ 01.ccx.0000216571.80944.65

56. Wartenberg KE, Schmidt JM, Claassen J, Temes RE, Frontera JA, Ostapkovich N, Parra A, Connolly ES, Mayer SA (2006) Impact of medical complications on outcome after subarachnoid hemorrhage. Crit Care Med 34:617-623; quiz 624. https://doi.org/10.1097/01. ccm.0000201903.46435.35

57. Whitmore RG, Stephen J, Stein SC, Campbell PG, Yadla S, Harrop JS, Sharan AD, Maltenfort MG, Ratliff JK (2012) Patient comorbidities and complications after spinal surgery: a societal-based cost analysis. Spine (Phila Pa 1976) 37:1065-1071. https://doi.org/10. 1097/BRS.0b013e31823da22d
58. Whitney NL, Selden NR (2012) Pullout-proofing external ventricular drains. J Neurosurg Pediatr 10:320-323. https://doi.org/10. 3171/2012.7.PEDS1280

59. Winkelman C (2007) Inactivity and inflammation in the critically ill patient. Crit Care Clin 23:21. https://doi.org/10.1016/j.ccc.2006.11. 002

60. Wu X, Li Z, Cao J, Jiao J, Wang Y, Liu G, Liu Y, Li F, Song B, Jin J, Liu Y, Wen X, Cheng S, Wan X (2018) The association between major complications of immobility during hospitalization and quality of life among bedridden patients: a 3 month prospective multicenter study. PLoS One 13:e0205729. https://doi.org/10.1371/ journal.pone.0205729

61. Yataco RA, Arnold SM, Brown SM, David Freeman W, Carmen Cononie C, Heckman MG, Partridge LW, Stucky CM, Mellon LN, Birst JL, Daron KL, Zapata-Cooper MH, Schudlich DM (2018) Early progressive mobilization of patients with external ventricular drains: safety and feasibility. Neurocrit Care. https://doi.org/10. 1007/s12028-018-0632-7

62. Young B, Moyer M, Pino W, Kung D, Zager E, Kumar MA (2019) Safety and feasibility of early mobilization in patients with subarachnoid hemorrhage and external ventricular drain. Neurocrit Care 31:88-96. https://doi.org/10.1007/s12028-019-00670-2

Publisher's note Springer Nature remains neutral with regard to jurisdictional claims in published maps and institutional affiliations. 